\title{
Comparative RNA-seq based transcriptome profiling of waterlogging response in cucumber hypocotyls reveals novel insights into the de novo adventitious root primordia initiation
}

\author{
Xuewen Xu, Minyang Chen, Jing Ji, Qiang Xu, Xiaohua Qi and Xuehao Chen*
}

\begin{abstract}
Background: Waterlogging is a serious abiotic stress to plant growth because it results in the decline in the supplement of oxygen to submerged tissues. Although cucumber (Cucumis sativus L.) is sensitive to waterlogging, its ability to generate adventitious roots (ARs) facilitates gas diffusion and increases plant survival when the oxygen concentration is decreased. To gain a better understanding of the molecular mechanisms that enable de novo AR primordia emergence upon waterlogging, the RNA sequencing-based transcriptomic responses of two contrasting cucumber genotypes, Zaoer-N (waterlogging tolerant) and Pepino (waterlogging sensitive), which differed in their abilities to form AR were compared.

Results: More than 27,000 transcripts were detected in cucumber hypocotyls, from which 1494 and 1766 genes in 'Zaoer- $\mathrm{N}$ ' and 'Pepino', respectively, were differentially expressed 2 days after waterlogging. The significant positive correlation between RNA sequencing data and a qPCR analysis indicated that the identified genes were credible. A comparative analysis revealed that genes functioning in carbohydrate mobilization, nitrate assimilation, hormone production and signaling pathways, transcription factors and cell division might contribute to the waterloggingtriggered AR primordia initiation. Ethylene was determined to be an important plant hormone responsible for the cucumber ARs initiation. Additionally, genes encoding cytochrome P450, ankyrin repeat-containing proteins and sulfite oxidases were determined as important in waterlogging acclimation.
\end{abstract}

Conclusion: This research broadens our understanding of the mechanism underlying waterlogging-triggered ARs emergence, and provides valuable information for the breeding of cucumber with enhanced waterlogging tolerance.

Keywords: Cucumber, Waterlogging, Adventitious root primordia, RNA-seq, Ethylene

\section{Background}

Waterlogging occurs in many regions worldwide because of poor drainage and/or excessive rainfall $[1,2]$. The major plant symptoms caused by waterlogging include loss of plasma membrane integrity, leaf wilting, chlorosis and necrosis [3]. In addition, decreased growth rates and yields have been attributed to the lack of available oxygen required to support aerobic respiration, and the

\footnotetext{
* Correspondence: xhchen@yzu.edu.cn

Department of horticulture, School of Horticulture and Plant Protection,

Yangzhou University, 48 wenhui eastroad, Yangzhou, Jiangsu 225009, China
}

associated increase in temperature causes more damage [4]. To adapt to a waterlogging environment, some tolerant plants have evolved morphological adaptations, such as the formation of adventitious roots (ARs), formation of aerenchyma in existing tissues, and elongation of shoots, all of which improve the ability to supply oxygen to hypoxic tissues $[5,6]$.

ARs production is an important adaptive trait of waterlogging tolerance [7], because it allows the submerged tissues to obtain oxygen directly from the air. This characteristic has been reported in rice [8], Rumex [9], barley [10], 
maize [11], soybean [12] and Solanum dulcamara [6]. In most species, the waterlogging-induced ARs also contain highly porous tissues, such as extensive aerenchyma. AR formation is usually divided into four key steps: (i) cell dedifferentiation, (ii) cell division, (iii) AR primordia outgrowth and (iv) AR elongation [13]. In rice and $S$. dulcamara, AR primordia formed at the nodes as a part of the normal developmental program and grow at a very slow rate, resulting in larger root initials as the nodes age [14]. These dormant primordia become activated and emerge from the stem node within $8-10 \mathrm{~h}$ of partial waterlogging [15]. In case of deep-water rice, ethylene is released upon waterlogging, inducing the formation of the reactive oxygen species (ROS). This results in the death of cell in the epidermal cell layer that covers the AR primordia at the nodes, thereby facilitating their emergence $[14,16]$. A global gene expression study in S. dulcamara indicated that multiple hormones signaling pathways are likely to be involved by flooding and, therefore, may activate the dormant AR primordia [6]. However, in most dicotyledons, such as cucumber and tomato, no cells are specified to form ARs in hypocotyls or stems before induction [17]. In this case, continuous cell division, growth, and differentiation are essential to produce the AR primordia inside the hypocotyls [18]. To date, the mechanism responsible for waterlogging's effects on de novo AR primordia initiation and further development remain unclear.

Cucumber, Cucumis sativus L., is an economically important vegetable crop [2]. Cucumber has a shallow root system and strict oxygen requirement $[19,20]$. Thus, cucumber is generally considered as waterlogging sensitive, and is easily affected by heavy rain and subsequent periods of soil waterlogging [19]. In our screening of germplasm, we identified a cucumber landrace, 'Zaoer-N' that exhibited a high level of waterlogging tolerance [21]. In greenhouse waterlogging experiments, Zaoer- $\mathrm{N}$ produced large numbers of ARs on its hypocotyl, while almost no ARs were generated in the waterlogging-sensitive line Pepino. To further our understanding of the molecular mechanisms that enable de novo AR primordia emergence and to improve gas exchange upon an abiotic stress trigger, we analyzed the transcriptomic changes of these two contrasting cucumber genotypes that differed in waterlogging tolerance and in ARs formation capabilities [6]. Our findings will allow the identification of important genes involved in waterloggingtrigged AR formation in cucumber hypocotyls, resulting in important molecular resources for the further breeding of cucumber with an enhanced tolerance to waterlogging.

\section{Methods}

\section{Plant materials and stress conditions}

The waterlogging tolerant line Zaoer-N is a cucumber landrace originally collected from South China, and has been maintained in our laboratory for more than 20 years.
The waterlogging sensitive 'Pepino' is a North American processing market-type cucumber cultivar, which was kindly provided by U.S. National Plant Germplasm System (https://npgsweb.ars-grin.gov/gringlobal/search.aspx?).

'Zaoer-N' and 'Pepino' were grown in 8 -cm-wide pots containing vermiculite, peat and perlite $(1: 3: 1, v / v / v)$ in a greenhouse with a relative humidity ranging from 70 to $85 \%$ and $28{ }^{\circ} \mathrm{C} / 20{ }^{\circ} \mathrm{C}(14 \mathrm{~h} / 10 \mathrm{~h})$ day/night temperature. Upon the emergence of the third true leaves $(21 \mathrm{~d}$ after germination), the seedlings were transferred into plastic containers filled with water $(\mathrm{pH} 7.03$, dissolved oxygen level $7.17 \mathrm{mg} / \mathrm{L}$ and electrical conductivity of $0.34 \mathrm{dS} \mathrm{m}^{-1}$ ) to the top of hypocotyls $(\sim 4 \mathrm{~cm}$ above the soil surface with a soil redox potential of $272 \pm 4.5 \mathrm{mV}$ ). Water was kept constant throughout the experiment. For control treatments, plants were placed in containers with no water. Hypocotyls (below the water surface) were harvested from the 'Zaoer- $\mathrm{N}$ ' and 'Pepino' seedlings $2 \mathrm{~d}$ after treatment, frozen in liquid nitrogen, ground into powder and stored at $-80{ }^{\circ} \mathrm{C}$. There were three biological replicates for each sample, which consisted of 15 hypocotyls from 15 seedlings of the same line.

\section{Abscisic acid (ABA), indole-3-acetic acid (IAA) and ethyl- ene determinations}

The endogenous ABAand IAA contents were extracted and analyzed according to the methods of Großkinsky et al. [22] and Kim et al. [12]. Briefly, $0.8 \mathrm{~g}$ of frozen powder were extracted twice with $4 \mathrm{~mL}$ of extraction solution. After shaken for $30 \mathrm{~min}$ at $4{ }^{\circ} \mathrm{C}$, dichloromethane $(8 \mathrm{~mL})$ was added, and the mixture was further shaken at $4{ }^{\circ} \mathrm{C}$ for $30 \mathrm{~min}$ and centrifuged in an Eppendorf 5415D centrifuge (Eppendorf, Hamburg, Germany) for $5 \mathrm{~min}$ at $13,000 \mathrm{rpm}$. The lower organic phase was protected from light, dried under nitrogen, dissolved in methane acid and filtered using a $0.45-\mu \mathrm{m}$ membrane. The filtrated extract was then subjected to HPLC-MS/MS analysis using a reversed-phase ZORBAX SB-C18 (Agilent Technologies, Santa Clara, CA, USA) column $(150 \times 2.1 \mathrm{~mm} ; 3.5 \mu \mathrm{m}$ particle size $)$. The mobile phase A solvent consisted of $0.1 \%$ methanoic acid /methanol, and the mobile phase B solvent consisted of $0.1 \%$ methanoic acid/ultrapure water.

The fresh hypocotyl samples used in the ethylene analysis were from the same batches (before being frozen) used for the RNA-seq experiment. The washed samples were kept in 30-mL dark glass bottles for $30 \mathrm{~min}$. Then, $1 \mathrm{~mL}$ gas samples were injected into a gas chromatograph device equipped with a TRB-5 capillary column. Injection, detector and heat chamber temperatures were set at $150{ }^{\circ} \mathrm{C}, 150{ }^{\circ} \mathrm{C}$ and $100{ }^{\circ} \mathrm{C}$, respectively. The gas chromatograph was calibrated with standard ethylene to determine the exact retention time before each endogenous ethylene determination. 
RNA extraction, library construction and Illumina sequencing Total RNA was extracted from the hypocotyls of treatment and control seedlings of both lines using TRIzol reagent (Invitrogen, Carlsbad, CA, USA). We confirmed the RNA integrity using the 2100 Bioanalyzer (Agilent Technologies, USA). We measured the RNA concentration in a Qubit 2.0 fluorometer by the Qubit RNA Assay Kit (Life Technologies, Carlsbad, CA, USA). We prepared the Libraries from 100 ng of total RNA using an Illumina TruSeq RNA Sample Prep Kit (San Diego, CA, USA) following the manufacturer's protocol. In total, 12 libraries were sequenced using the Illumina Hiseq 2500 platform (San Diego, CA, USA). We pre-processed the raw reads by our in-house quality control pipeline. The clean sequence reads were then blasted to the 9930 reference genome (http://www.icugi.org/cgi-bin/ICuGI/ index.cgi), and then, the mRNA abundance levels of the unigenes identified using TopHat v2.0.9 and Cufflinks [23] were normalized by the Fragments Per Kilobase of exon model per Million mapped reads (FPKM) [24], and the $\log 2$ fold changes between two samples were tested statistically to determine whether an individual gene's expression was altered significantly. We used the criteria of false discovery rate (FDR) $<0.01$ and fold changes $<0.5$ or $>2.0(<-1$ or $>1$ in $\log 2$ ratio value) to identify the differentially expressed genes (DEGs).

\section{Quantitative PCR (qPCR) analysis}

To validate the RNA-seq results, a subset of DEGs were verified by $\mathrm{qPCR}$. An independent set of samples was harvested at $48 \mathrm{~h}$ after waterlogging, and a corresponding control was used for the expression analysis. Sequences for each gene from the 9930 genome database (http://www.icugi.org/cgi-bin/ICuGI/index.cgi) were used to design primers with the online Primer 3 tool (http:// bioinfo.ut.ee/primer3-0.4.0/; Additional file 1: Table S1). The expression levels of 15 cucumber genes were tested using the RealMasterMix (SYBR Green) kit (Tiangen, China) following the manufacturer's protocol with an $\mathrm{iQ}^{\mathrm{m}}$ 5 Multicolor real-time PCR detection system (Bio-RAD, USA). To verify the presence of specific products, melting curve analyses of amplification products were executed following each PCR reaction.

\section{Results and discussion}

'Zaoer- $\mathrm{N}$ ' and 'Pepino' have contrasting responses, reflecting their waterlogging tolerance difference

Extended waterlogging periods result in the survival of selected cultivars or species [25]. The waterlogging-tolerant line 'Zaoer-N' is a landrace collected from South China where crop plants are subjected to frequent waterlogging or flooding events. The high frequency and long duration of waterlogging stress experienced by 'Zaoer- $\mathrm{N}$ ' has led to a strongly selected for plants with greater levels of low oxygen and waterlogging tolerance compared with those of 'Pepino'. A visual contrasting survival strategy adopted during the seedling stage is the capacity for AR formation in hypocotyls, which is shown in Fig. 1 and Additional file 2: Fig. S1. No AR primordia were observed in either genotype before the waterlogging treatment (Fig. 1a, b), which was different from previous reports on rice and $S$. dulcamara $[6,26]$. In these species, AR primordia were constitutively present on the stem or internodes before waterlogging. Here, AR primordia were visible only on the hypocotyl surfaces of 'Zaoer-N' 2 days after waterlogging, compared with control plants and waterlogged 'Pepino' (Fig. 1c, d). Seven days after treatment, the average AR numbers protruding from the basal parts of 'Zaoer-N' and

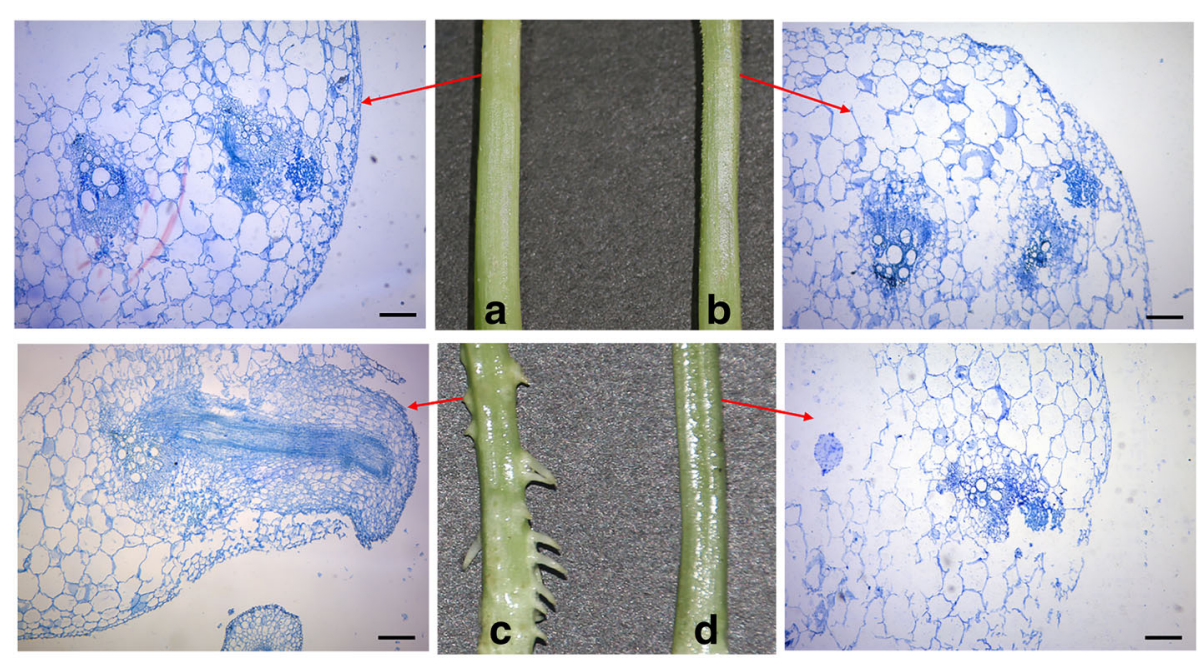

Fig. 1 Adventitious root formation on hypocotyls of cucumber seedlings. a Zaoer-N control; b Pepino control; c Zaoer-N waterlogging; d Pepino waterlogging. The water level was kept at about $4 \mathrm{~cm}$ (to the base of the first true leaves) above the soil for 2 days and then removed for photography 
'Pepino' hypocotyls were 30.4 and 2.8, respectively (Additional file 2: Fig. S1). To elucidate the molecular changes that occurred during AR emergence in cucumber, plants were waterlogged for 2 days and the hypocotyls tissues were then dissected separately from 'Zaoer-N' and 'Pepino' for RNA-seq analysis.

\section{Waterlogging causes extensive transcriptomic reprogramming}

After removing the unknown (the proportion of undetermined bases $>10 \%$ ), low-quality and adaptor-containing reads, at least 28.3 million clean reads were obtained for each sample (Table 1). The clean reads were subsequently mapped to the cucumber 9930 genome assembly Ver. 2 [27]. In total, the expression of 27,058 transcripts was detected. Approximately $87 \%$ of the clean reads were mapped to the reference genome, with more than $83 \%$ of them being uniquely mapped (Table 1 ). Using a fold change $\geq 2$ and FDR $\leq 0.01$ as cut-offs, 1494 (Additional file 3: Table S2) and 1766 (Additional file 4: Table S3) DEGs were identified in the pairwise comparisons of 'Zaoer- $\mathrm{N}$ ' waterlogging vs. 'Zaoer-N' control and 'Pepino' waterlogging vs. 'Pepino' control, respectively, indicating that a large number of genes were waterlogging responsive. In total, 993 DEGs (579 up-regulated and 414 down-regulated in abundance) were shared between the two lines. Additionally, 499 DEGs (281 up-regulated and 218 down-regulated) were only identified in 'Zaoer-N', and 771 DEGs (318 up-regulated and 453 down-regulated) were only identified in 'Pepino'. Only two DEGs (Csa5G153010 and Csa5G305760) showed opposite regulatory states in the two lines (Fig. 2). To validate the RNA-seq data, 15 randomly selected DEGs were subjected to qPCR analyses. As shown in Fig. 3, there was a

Table 1 Mapping results of RNA sequencing reads of the cucumber 'Zaoer- $\mathrm{N}$ ' and 'Pepino' $48 \mathrm{~h}$ after waterlogging (WL) treatment and relative non-waterlogged conditions (CK)

\begin{tabular}{lllll}
\hline Sample ID & Total reads & $\begin{array}{l}\text { Mapped } \\
\text { reads }\end{array}$ & $\begin{array}{l}\text { Uniquely } \\
\text { mapped reads }\end{array}$ & $\begin{array}{l}\text { Number of } \\
\text { mapped genes }\end{array}$ \\
\hline Pepino CK_1 & $33,225,482$ & $29,848,764$ & $28,965,262$ & 19,723 \\
Pepino CK_2 & $46,772,956$ & $41,794,366$ & $40,689,862$ & 21,056 \\
Pepino CK_3 & $37,596,070$ & $33,665,760$ & $32,653,010$ & 19,991 \\
Pepino WL_1 & $36,258,376$ & $32,161,091$ & $29,798,229$ & 20,038 \\
Pepino WL_2 & $36,982,414$ & $32,480,793$ & $30,615,432$ & 20,052 \\
Pepino WL_3 & $41,844,460$ & $35,644,650$ & $29,096,668$ & 20,247 \\
Zaoer-N CK_1 & $43,620,302$ & $37,461,442$ & $34,791,432$ & 20,050 \\
Zaoer-N CK_2 & $35,427,694$ & $30,387,272$ & $29,598,977$ & 19,870 \\
Zaoer-N CK_3 & $39,279,546$ & $34,107,693$ & $33,275,553$ & 20,013 \\
Zaoer-N WL_1 & $42,364,332$ & $36,674,382$ & $35,372,191$ & 20,346 \\
Zaoer-N WL_2 & $28,383,702$ & $2,4680,987$ & $23,953,530$ & 19,918 \\
Zaoer-N WL_3 & $36,077,522$ & $31,208,030$ & $30,126,104$ & 20,145 \\
Average & $38,152,738$ & $33,342,936$ & $31,578,021$ & 20,121 \\
\hline
\end{tabular}

strong positive correlation (two tailed, $\mathrm{R}^{2}=0.96$ ) between the RNA-seq data and qPCR data, indicating that the RNA-seq data were credible.

\section{Functional annotation of waterlogging-responsive DEGs}

To dissect the processes taking place during the AR primordia emergence under waterlogging conditions, we peformed a gene ontology (GO) enrichment analysis. The top five most significantly enriched GO terms are shown in Fig. 2. The GO terms 'response to chemical stimulus' and 'oxidoreductase activity' were highly enriched in the DEGs that were commonly up-regulated in 'Zaoer-N' and 'Pepino', whereas 'regulation of cellular process' and 'regulation of metabolic process' were highly enriched in the DEGs that were commonly down-regulated in the two lines. The physical challenge of oxygen deprivation under waterlogging is reflected in these metabolic changes, in which both lines appear to activate reserve mobilization and down-regulate energy-consuming processes. The GO term 'peroxidase activity' was highly enriched in the DEGs that were specifically up-regulated in 'Zaoer-N', but 'cell death' was dramatically enriched in those specifically upregulated in 'Pepino'. The impairment of photosynthesis under waterlogging generally leads to metabolic imbalances and, thus, the production of ROS and toxic byproducts [28]. The overrepresentation of GO terms associated with peroxidase activity in 'Zaoer-N' suggested enhanced ROS scavenging during AR emergence. ROS at lower concentrations may act as signaling molecules involved in the acclimation to environmental stress, but high levels of these compounds are also harmful to plant cells, which was reflected in the additional activation of the 'cell death' GO term in 'Pepino' [29]. The GO term 'external encapsulating structure', which refers to a structure that lies outside the plasma membrane and surrounds the entire cell, was also highly enriched in the genes that were specifically up-regulated in 'Zaoer-N' [30]. This enrichment suggested that AR emergence in 'Zaoer- $N$ ' hypocotyls was associated with cell reconstruction. Furthermore, there was a strong overrepresentation of the GO term 'nitrogen compound metabolic process' in the down-regulated DEGs of 'Pepino'. The beneficial effects of the metabolism of nitrogen-containing compounds in plants under waterlogging conditions involve $\mathrm{NAD}^{+}$regeneration, ATP synthesis and cytosolic acidification [31]. Compromising the expression of genes involved in the nitrogen compound-related metabolic processes could further block the ATP supply and reduce the cytoplasmic $\mathrm{pH}$ in 'Pepino' hypocotyls.

\section{Differential regulation of genes associated with energy production}

Because oxygen-dependent mitochondrial respiration is greatly limited under waterlogging conditions, the 


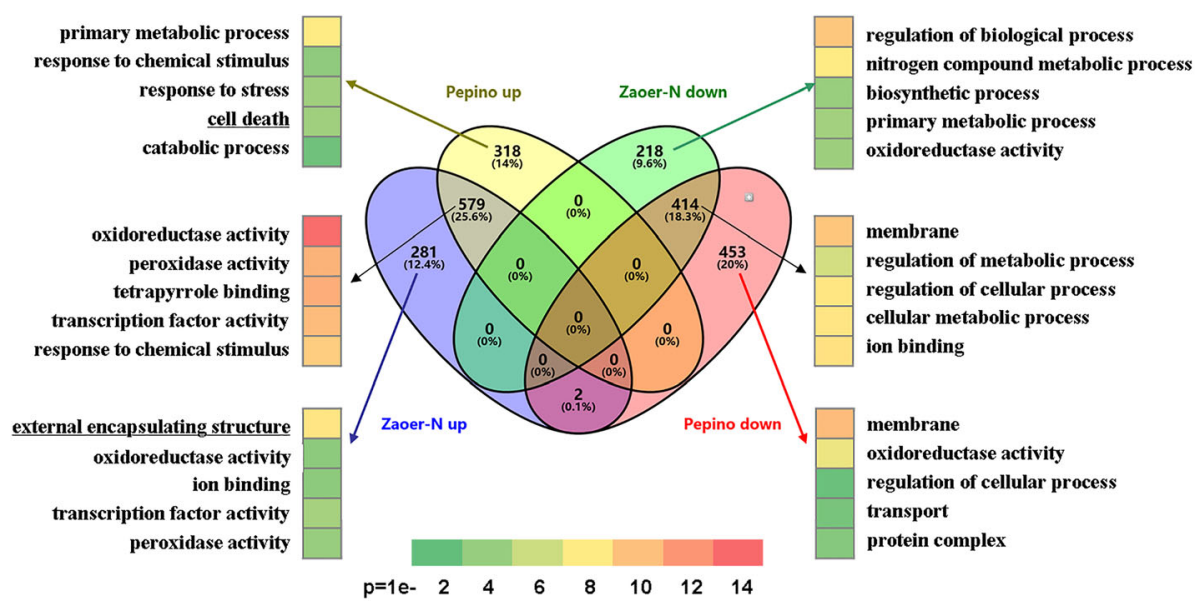

Fig. 2 Venn diagram of all genes expressed in hypocotyls of Zaoer-N and Pepino upon waterlogging (false discovery rate $\leq 0.01$ and fold change $\geq 2$ ) and their respective top five most significantly enriched Gene Ontology (GO) terms

acceleration of carbohydrate metabolism is functionally conserved among both sensitive and tolerant plants, and is critical for plant survival [32]. As expected, we found that several DEGs, such as glucose-6-phosphate 1epimerase (Csa4G050850), pyruvate kinase (Csa5G580610 and Csa6G449830), 6-phosphogluconate dehydrogenase (Csa5G642720), triose phosphate isomerase (Csa4G59 8000) and phosphofructokinase (Csa4G664520), which are involved in glycolysis, and alcohol dehydrogenase ( $A D H$; Csa7G320050) and pyruvate decarboxylase (PDC; Csa3G 730980 and Csa6G518930), which are involved in ethanol fermentation were significantly accumulated in both 'Zaoer-N' and 'Pepino', suggesting the common regulation of energy generation in waterlogged cucumber hypocotyls.

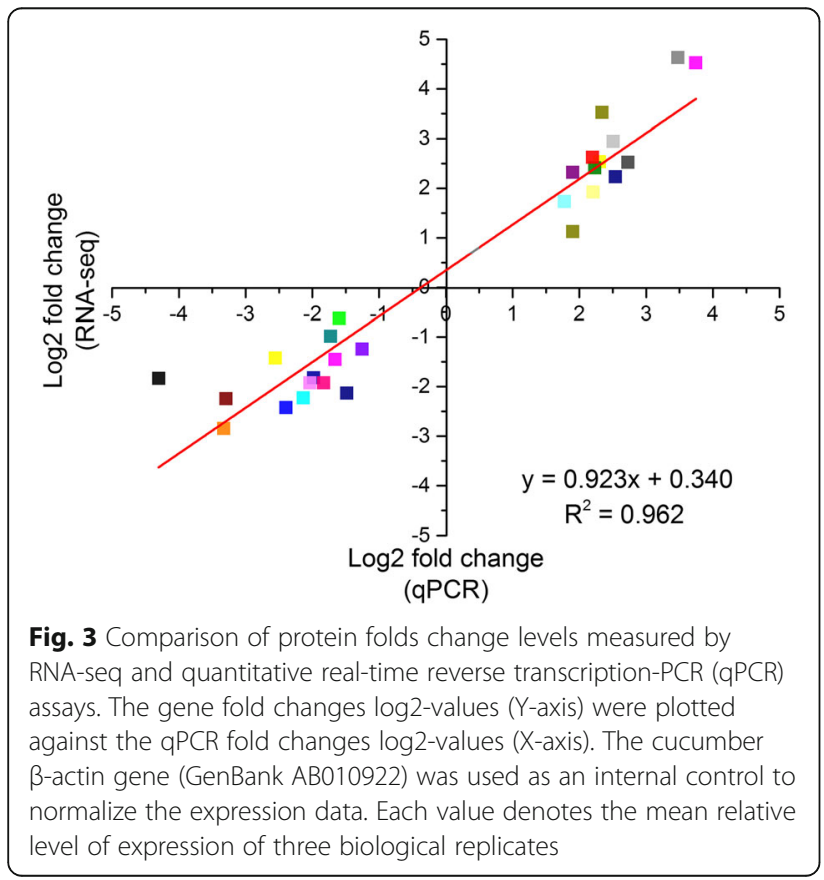

The maintenance of the adenylated energy charge is dependent on the availability of substrates for the glycolytic and fermentative pathway, such as glucose, fructose or pyruvate. Sucrose synthase is a key enzyme for the hydrolysis of sucrose, and it plays a important role in providing an adequate sugar supply during waterlogging [33]. Ricard et al. [34] found that maize sucrose synthase mutants are less tolerant to oxygen deficits than the wild-type. Wang et al. [35] reported that the overexpression of sucrose synthase in cucumber confers tolerance to hypoxic conditions. Here, the gene (Csa1G597800) encoding sucrose synthase was highly up-regulated in tolerant 'Zaoer- $\mathrm{N}$ ' but remained unchanged in susceptible 'Pepino'. In addition to sucrose synthase, genes encoding aspartate aminotransferase (EC2.6.1.1, Csa3G88 9160) and alanine aminotransferase (EC2.6.1.2, Csa3G6 46610), which are involved in pyruvate regeneration by affecting the amount of oxaloacetic acid [36], were also induced at higher levels in hypocotyl cells of 'Zaoer-N' than 'Pepino' seedlings under waterlogging conditions. Consequently, 'Zaoer-N', which sustained adequate supplies of readily useable sugars and additional pyruvate generation from amino acid metabolism, had a greater energy state and chance of survival than 'Pepino', which was lacking in these areas.

Stoimenova et al. [37] found that plant mitochondria are capable of anaerobic ATP synthesis with NADH and NADPH as electron donors and nitrite as a terminal electron acceptor, replacing oxygen in the respiratory chain. Nitrate is the main nitrogen source for most plants, and its application increased the survival of tomato and Hevea brasiliensis subjected to waterlogging [31, 38]. Plants take up nitrate from the soil using transporters in the plasma membrane of root epidermal and cortical cells. In waterlogged cucumber hypocotyls, 11 and 12 DEGs encoding nitrate transporters (NRTs) were 
identified respectively in 'Zaoer-N' and 'Pepino', emphasizing the roles of nitrate in waterlogging acclimation. Because seven of the 11 NRTs in 'Zaoer-N' were upregulated, while eight of the 12 NRTs in 'Pepino' were down-regulated (Table 2), nitrate may be assimilated to a greater degree in waterlogged 'Zaoer-N' hypocotyls (Table 2). The extra assimilated nitrate could be used as $\mathrm{NADH}$ acceptors, providing an alternative to fermentation during waterlogging. The denitrification has some advantages for survival and AR emergence if it operates in conjunction with a means of removing the toxic byproduct nitric oxide (NO), an important factor in cell death induction [39]. The non-symbiotic hemoglobins (nsHBs) could function in this regard. Perazzolli et al. [40] found that Arabidopsis AtnsHB1, scavenges NO through the production of S-nitrosohemoglobin and reduces $\mathrm{NO}$ emission under hypoxic stress, indicating its role in NO detoxification. Here, we observed that two nsHBs (Csa2G238880 and Csa2G375770) were commonly upregulated in both genotypes and their expression levels were greater higher in the waterlogged 'Zaoer-N' hypocotyls (Table 2). Thus, 'Zaoer-N', with its efficient metabolic mechanisms associated with carbohydrate mobilization and nitrogen assimilation, may be more suited to face oxygen deprivation and generate AR primordia. This speculation is in accordance with our previous measurements in which a 2-d waterlogging treatment led to greater increases in PDC and $\mathrm{ADH}$ activities, as well as ethanol concentrations, in the hypocotyls of 'Zaoer-N' than in those of 'Pepino' [2]. However, additional biochemical testing is needed to confirm the importance of nitrogen assimilation on plant survival under waterlogging stress.

\section{Hormonal regulation of AR emergence in waterlogged cucumber}

Ethylene is a major hormone of waterlogging-induced AR emergence [41]. In the submergence-tolerant species $S$. dulcamara, submergence for $24 \mathrm{~h}$ induces a significantly increase in ethylene emission that in turn promotes the activation of AR primordia, which can be delayed by a pretreatment with the ethylene-perception inhibitor 1-methylcyclopropene (1-MCP) [6]. Accordingly, we measured the endogenous ethylene production of the waterlogged hypocotyls. Increase in ethylene release $48 \mathrm{~h}$ after waterlogging of $\sim 5.7$-fold and 2.3-fold were observed in 'Zaoer- $\mathrm{N}$ ' and 'Pepino', respectively (Fig. 4). In our previous study, we found that the AR primordia generated on 'Zaoer-N' hypocotyls after waterlogging were significantly inhibited when pretreated with $100 \mathrm{mg} / \mathrm{L} 1-\mathrm{MCP}$ as an inhibitor of ethylene action [42], indicating the importance of

Table 2 Comparisons of the expression levels of representative nitrate transporter genes and non-symbiotic hemoglobin genes involved in nitrate assimilation and NO scavenging. 'ND' represents not detected

\begin{tabular}{|c|c|c|c|c|c|}
\hline \multirow[t]{2}{*}{ Gene ID } & \multicolumn{2}{|c|}{ Z WL vs Control } & \multicolumn{2}{|c|}{ P WL vs Control } & \multirow[t]{2}{*}{ Functional annotation } \\
\hline & $\log 2 \mathrm{FC}$ & FDR & Log2FC & FDR & \\
\hline Csa1G008530 & -1.54 & $1.46 \mathrm{E}-08$ & -1.36 & $2.78 \mathrm{E}-04$ & nitrate transporter 2.11 \\
\hline Csa2G374640 & -2.81 & $2.39 \mathrm{E}-06$ & -1.78 & $1.58 \mathrm{E}-03$ & nitrate transporter 1.2-like \\
\hline Csa4G007610 & -1.71 & $1.30 \mathrm{E}-07$ & -1.51 & $1.93 \mathrm{E}-05$ & nitrate transporter 6.1 \\
\hline Csa3G027720 & 2.61 & $1.95 \mathrm{E}-04$ & 2.48 & $5.24 \mathrm{E}-18$ & nitrate transporter 1.1-like \\
\hline Csa3G134770 & -2.15 & $2.29 \mathrm{E}-04$ & 1.39 & $1.29 \mathrm{E}-03$ & nitrate transporter 5.2-like \\
\hline Csa5G161290 & 7.05 & $1.10 \mathrm{E}-06$ & 7.42 & $3.41 \mathrm{E}-15$ & nitrate transporter 6.3-like \\
\hline Csa1G324370 & ND & ND & -1.08 & $8.85 \mathrm{E}-04$ & nitrate transporter 6.2-like \\
\hline Csa2G172510 & ND & ND & -1.07 & $1.85 \mathrm{E}-05$ & nitrate transporter 5.2 \\
\hline Csa2G416080 & ND & ND & -1.52 & $1.55 \mathrm{E}-04$ & nitrate transporter 6.4 \\
\hline Csa3G112250 & ND & ND & -2.11 & 4.16E-05 & nitrate transporter 4.3 \\
\hline Csa5G647280 & ND & ND & -1.43 & $8.19 \mathrm{E}-05$ & nitrate transporter 4.4 \\
\hline Csa3G904070 & ND & ND & 1.04 & 1.59 E-03 & nitrate transporter 7.3-like \\
\hline Csa3G134760 & 2.45 & $6.97 \mathrm{E}-04$ & ND & ND & nitrate transporter 5.3 \\
\hline Csa6G037500 & 1.23 & $1.53 \mathrm{E}-05$ & ND & ND & nitrate transporter 3.1 \\
\hline Csa6G404120 & 1.16 & $7.62 \mathrm{E}-03$ & ND & ND & nitrate transporter 4.6-like \\
\hline Csa5G219390 & 1.24 & $2.96 \mathrm{E}-05$ & ND & ND & nitrate transporter 5.1 \\
\hline Csa6G187970 & 1.31 & $3.13 \mathrm{E}-06$ & ND & ND & nitrate transporter $Y 8.1$ \\
\hline Csa2G238880 & 3.38 & $2.43 \mathrm{E}-20$ & 2.45 & $2.27 \mathrm{E}-07$ & non-symbiotic hemoglobin 1 \\
\hline Csa2G375770 & 3.29 & 1.81E-06 & 2.83 & $1.51 \mathrm{E}-27$ & non-symbiotic hemoglobin 3 \\
\hline
\end{tabular}



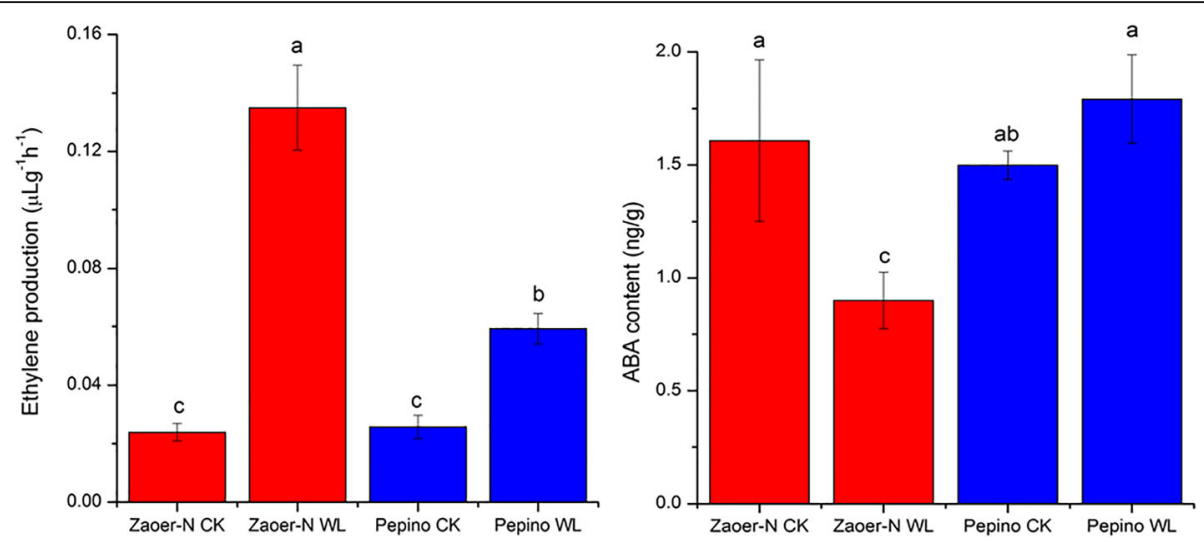

Fig. 4 Ethylene production (left) and endogenous ABA (right) in Zaoer-N and Pepino 2 days after waterlogging treatment. 'WL' and 'CK' represent waterlogging treatment and control. Data is the average \pm standard error $(n=3)$. Means with the same lowercase letter do not significantly differ by the least significant difference (LSD) test at $p \leq 0.05$ with a completely randomized design

ethylene in waterlogging-triggered cucumber AR production. Ethylene is biosynthesized from methionine, and it is produced by the activation of 1-aminocyclopropane-1-carboxylicacid synthase (ACS) and ACC oxidase (ACO) [43]. The transcriptome-wide analysis showed that transcripts of an ACS (Csa4G049610) and three ACO (Csa2G000520, Csa4G056660 and Csa6G421630) accumulated in both lines, but the gene inductions in 'Zaoer-N' were greater, which was in line with the observed difference in ethylene production. Ivanchenko et al. [44] also found that enhanced ethylene synthesis promotes the initiation of Arabidopsis lateral root primordia.

The environmental stress-associated hormone ABA is a known inhibitor of lateral roots development that acts at the post-emergence stage $[12,45]$. Contrary to the case of ethylene, ABA responses were down-regulated upon waterlogging according to our transcriptome analysis. Two DEGs (Csa4G064690 and Csa6G523440) encoding 9-cis epoxycarotenoid dioxygenase (NCED) were especially repressed in 'Zaoer-N'. NCED catalyzes the cisviolaxanthin to xanthoxin, a direct precursor of $\mathrm{ABA}$ synthesis [46] and, therefore, may contribute to a reduction in ABA, providing conditions favorable for AR induction. A strong decrease in carotenoid cleavage dioxygenase (Csa4G056640), which may also include NCEDs, was observed in 'Zaoer-N' only. To confirm this, the endogenous ABA content 2 days after waterlogging treatment were determined, and the ABA level in waterlogged 'Zaoer-N' hypocotyls decreased approximately $63.9 \%$ in comparison with the control, whereas there was no significant difference in 'Pepino' (Fig. 4). This indicates that the maintenance of ABA levels could facilitate AR growth suppression in 'Pepino'. The decrease in the ABA levels in 'Zaoer-N' may result from the ethylene accumulation, which has been reported in plant species such as soybean [12] and Rumex palustris [47].
Based on functional annotations, there were 29 (17 down-regulated and 11 up-regulated) and 30 (17 downregulated and 13 up-regulated) DEGs in 'Zaoer-N' and 'Pepino', respectively, that were involved in auxin metabolism (Table 3). These included transcripts encoding IAA-amido synthetases (GH3s), auxin efflux carrier components (PIN), indole-3-pyruvate monooxygenase YUCCA (YUC), auxin response factors (ARF) and auxin-induced or -responsive proteins. GH3 is of special interest because it is an adenylate-forming enzyme in plants that conjugates amino acids to auxin, providing a negative feedback loop to control auxin homoeostasis [48]. The overexpression mutants GH3-6/DFL1 [49] and GH3-2/YDK1 [50] display dwarf phenotypes consistent with decreased levels of free auxin in these plants. A strong induction of GH3s (Csa6G493310, Csa4G 007100 and Csa3G198490) was found in both genotypes under waterlogging stress, indicating that the mechanisms associated with auxin storage were important negative regulatory genes for AR initiation in cucumber hypocotyls. Auxin directs plant morphogenesis through the differential accumulation within tissues, which depends largely on the activity of PIN proteins that mediate the auxin efflux from cells and thus directional cell-to-cell transport [51]. The Arabidopsis triple mutant PIN1PIN3PIN4 displays defects in primary root development [52]. The PIN2-RNA interference lines in S. dulcamara delayed AR emergence upon flooding [6]. Among the four PINs (Csa1G025070, Csa1G042820, Csa4G4 30820 and Csa5G576590) identified in our transcriptome data, Csa1G025070 and Csa1G042820 were commonly down-regulated in both genotypes, while Csa4G4 30820 was specifically accumulated in 'Zaoer-N', and Csa5G576590 was specifically decreased in 'Pepino'. We hypothesized that the up-regulation of PIN (Csa4G 430820) in 'Zaoer-N' may contribute to basipetal auxin 
Table 3 Comparisons of the expression levels of representative differentially expressed genes involved in auxin metabolism. 'ND' represents not detected

\begin{tabular}{|c|c|c|c|c|c|}
\hline \multirow[t]{2}{*}{ Gene ID } & \multicolumn{2}{|c|}{ Z WL vs Control } & \multicolumn{2}{|c|}{ P WL vs Control } & \multirow[t]{2}{*}{ Functional annotation } \\
\hline & $\overline{\log 2 \mathrm{FC}}$ & FDR & Log2FC & FDR & \\
\hline Csa3G198490 & ND & ND & 1.84 & $2.45 \mathrm{E}-03$ & Indole-3-acetic acid-amido synthetase GH3.1 \\
\hline Csa4G007100 & 2.53 & 1.07E-11 & 1.33 & $1.63 \mathrm{E}-03$ & Indole-3-acetic acid-amido synthetase GH3.7 \\
\hline Csa6G493310 & 2.79 & 1.86E-08 & ND & ND & indole-3-acetic acid-amido synthetase GH3.1 \\
\hline Csa1G025070 & -1.24 & $7.86 \mathrm{E}-06$ & -1.46 & 5.93E-08 & Auxin efflux carrier component 1 \\
\hline Csa1G042820 & -1.21 & $3.22 \mathrm{E}-06$ & -1.05 & $3.58 \mathrm{E}-05$ & Auxin efflux carrier component 1 \\
\hline Csa4G430820 & 1.57 & $7.53 \mathrm{E}-04$ & ND & ND & Auxin efflux carrier component $1 c$ \\
\hline Csa5G576590 & ND & ND & -1.46 & 4.09E-08 & Auxin efflux carrier component 3 \\
\hline Csa1G051690 & 1.99 & $4.17 \mathrm{E}-03$ & ND & ND & Indole-3-acetic acid-induced protein ARG7 \\
\hline Csa5G534970 & ND & ND & -1.89 & $9.77 \mathrm{E}-04$ & Indole-3-acetic acid-induced protein ARG5 \\
\hline Csa6G452710 & 6.07 & $2.51 \mathrm{E}-08$ & 5.07 & $2.38 \mathrm{E}-17$ & Indole-3-acetic acid-induced protein ARG7 \\
\hline Csa1G207820 & -1.51 & 4.6 E-05 & -1.17 & $9.23 \mathrm{E}-05$ & Auxin-responsive protein IAA13 \\
\hline Csa1G397130 & ND & ND & 3.18 & $9.69 \mathrm{E}-06$ & Auxin-responsive protein IAA16 \\
\hline Csa2G059200 & ND & ND & 1.75 & $2.85 \mathrm{E}-04$ & Auxin-responsive protein IAA33 \\
\hline Csa2G170820 & ND & ND & -1.79 & $1.11 \mathrm{E}-11$ & Auxin-responsive protein IAA13 \\
\hline Csa2G200420 & -1.42 & 7.4 E-03 & ND & ND & Auxin-responsive protein \\
\hline Csa3G134550 & ND & ND & -1.25 & 4.61E-05 & Auxin-responsive protein IAA13 \\
\hline Csa3G143580 & -1.09 & $3.23 \mathrm{E}-03$ & ND & ND & Auxin-responsive protein IAA4 \\
\hline Csa3G877650 & -1.22 & 7.92E-04 & ND & ND & Auxin-responsive protein IAA29 \\
\hline Csa6G497220 & 1.11 & $1.13 \mathrm{E}-04$ & ND & ND & Auxin-responsive protein IAA9 \\
\hline Csa2G258720 & -2.56 & 4.09 E-03 & ND & ND & Auxin-induced protein $6 \mathrm{~B}$ \\
\hline Csa2G258760 & 2.62 & $7.53 \mathrm{E}-05$ & ND & ND & Auxin-induced protein X10A \\
\hline Csa2G379350 & ND & ND & -1.85 & 4.50 E-06 & Indole-3-pyruvate monooxygenase YUCCA4 \\
\hline Csa3G118740 & -1.09 & $2.65 \mathrm{E}-05$ & -1.42 & 8.34E-08 & Auxin-induced protein X15 \\
\hline Csa3G171820 & -1.03 & $1.83 \mathrm{E}-03$ & ND & ND & Auxin-induced protein \\
\hline Csa3G821040 & ND & ND & 3.89 & $3.09 \mathrm{E}-06$ & Auxin-regulated gene \\
\hline Csa3G866530 & ND & ND & 2.64 & $2.66 \mathrm{E}-04$ & Auxin-induced protein $6 \mathrm{~B}$ \\
\hline Csa3G883020 & ND & ND & 2.34 & $1.07 \mathrm{E}-04$ & Auxin-induced protein 6B \\
\hline Csa4G308640 & ND & ND & -1.20 & $3.00 \mathrm{E}-06$ & Auxin transporter-like protein 4 \\
\hline Csa4G433470 & ND & ND & 3.85 & $1.35 \mathrm{E}-06$ & Auxin-regulated gene I \\
\hline Csa4G556180 & -1.55 & $5.03 \mathrm{E}-04$ & -2.02 & $3.41 \mathrm{E}-09$ & Auxin-induced protein 6B OS \\
\hline Csa5G623890 & ND & ND & 1.52 & $1.10 \mathrm{E}-04$ & Auxin-regulated gene \\
\hline Csa6G092560 & 2.32 & $1.22 \mathrm{E}-10$ & 2.08 & $1.54 \mathrm{E}-16$ & Auxin-induced protein 15A \\
\hline Csa6G291920 & -1.11 & $3.99 \mathrm{E}-06$ & -1.10 & $1.72 \mathrm{E}-05$ & Auxin response factor 4 \\
\hline Csa6G518000 & -1.44 & $3.09 \mathrm{E}-03$ & ND & ND & Auxin-repressed $12.5 \mathrm{kDa}$ protein \\
\hline Csa6G518210 & -1.07 & $1.81 \mathrm{E}-05$ & -1.07 & $6.00 \mathrm{E}-05$ & Auxin response factor 3 \\
\hline Csa7G008430 & 1.19 & $4.21 \mathrm{E}-04$ & ND & ND & Auxin-induced protein $15 \mathrm{~A}$ \\
\hline Csa7G009020 & -2.40 & $4.67 \mathrm{E}-05$ & ND & ND & Auxin-induced protein $\mathrm{X} 10 \mathrm{~A}$ \\
\hline Csa7G009150 & 2.50 & $1.39 \mathrm{E}-05$ & 2.54 & $2.40 \mathrm{E}-04$ & Auxin-induced protein 10A5 \\
\hline Csa7G010800 & ND & ND & -1.30 & $1.71 \mathrm{E}-06$ & Auxin transporter-like protein 5 \\
\hline Csa7G329330 & -1.20 & $5.00 \mathrm{E}-06$ & -1.33 & $2.39 \mathrm{E}-03$ & Auxin response factor 9 \\
\hline Csa7G378520 & -1.34 & $2.39 \mathrm{E}-03$ & ND & ND & Auxin-induced protein AUX28 \\
\hline Csa7G448680 & 2.92 & $6.39 \mathrm{E}-15$ & 1.68 & 4.30E-05 & Auxin responsive protein \\
\hline
\end{tabular}


transport to the hypocotyl meristem, thereby, promoting AR primordia emergence. Additionally, the crucial gene YUC4 (Csa2G379350) for auxin biosynthesis was downregulated in the hypocotyls of 'Pepino'. There are 11 YUC family genes in the Arabidopsis genome [53]. The overexpression of each $Y U C$ in transgenic Arabidopsis plants leads to auxin overproduction, but the disruption of these $Y U C$ genes leads to defects in embryogenesis, seedling growth, flower development, and vascular pattern formation [54, 55]. The down-regulation of YUC4 in 'Pepino' may at least partially account for the compromised ability to induce AR. However, not all auxin-induced genes act as positive regulators during AR formation, and many of them were also found to be down-regulated in 'Zaoer-N', especially those genes encoding ARFs (Csa7G329330, Csa6G518210 and Csa6G291920) and auxin transporters (Table 3). de Jong et al. [56] found that SIARF9 negatively controls cell division during early tomato fruit growth. A transgenic line that over-expressed SIARF9 formed smaller fruits than wildtype, whereas a transgenic line that had a reduced SIARF9 mRNA expression level showed the opposite phenotype. Wang et al. [57] found a large number of genes involved in auxin transport were downregulated during indole-3butyric acid-induced AR formation in softwood cuttings of Catalpa bungei. An in-depth functional analysis of these downregulated auxin metabolism-related DEGs is required to further reveal their exact roles in AR formation.

\section{Responses of transcription factors (TFs) to waterlogging}

TFs are a group of DNA-binding proteins that control target gene expression by specifically binding to cisacting elements in their promoters and, as such, play essential roles in multiple cellular processes, such as development, cell cycle regulation, transcription regulation and responses to environmental stress [58]. In total 214 waterlogging-regulated TFS were identified according to their assigned gene families, which accounted for $~ 10 \%$ of the total DEGs (Additional file 5: Table S4). Of these, 107 TFs (66 up-regulated and 41 down-regulated) were commonly regulated in 'Zaoer-N' and 'Pepino', whereas 41 TFs (19 up-regulated and 22 down-regulated) were regulated in 'Zaoer-N' only, and 66 TFs (28 up-regulated and 38 down-regulated) were regulated in 'Pepino' only. Remarkably, ethylene response factor (ERFs, 32 DEGs) and WRKYs (17 DEGs) were included in the upregulated group, while DNA-binding with one finger (Dof, 8 DEGs) was included in the down-regulated group (Fig. 5a). These data strongly suggested the essence of transcriptional regulation in response to waterlogging. An in-depth analysis of these waterlogging-responsive $T F s$ is required to further provide candidate genes for improving waterlogging tolerance in cucumber.

Plant-specific group VII ERFs have emerged as pivotal modulators of the anaerobic responses under waterlogging conditions [59]. For example, the rice SUBMERGENCE $1 A$ gene confers prolonged submergence tolerance [60]. A HMMER-based search against the cucumber genome using the AP2/ERF domain (IPR001471) and N-end motif [MCGAII(A/S)] as queries identified five group VII ERF genes (Csa4G001970, Csa7G448110, Csa3G646560, Csa 6G318160 and Csa3G164580) (Fig. 5b). Consistent with activated ethylene synthesis, four group VII $E R F \mathrm{~s}$ were induced at higher levels in 'Zaoer-N' than in 'Pepino' (Fig. 5c), which indicates that the increased transcription of these genes could mechanistically explain hypoxic priming by ethylene [59]. Hypoxia responsive ERF 1 (HRE1), HRE2 and RAP2.12, three Arabidopsis ERF-VII genes, improved waterlogging tolerance by directly activating the low oxygen responsive marker gene $A D H[61,62]$. Whether the proteinto-protein interaction effect also existed in cucumber hypocotyls when waterlogged has yet to be further validated.

\section{Increased cellular activity upon waterlogging}

Here, the transcriptome profiling confirmed the activation of cell division during the initial stage of AR emergence in waterlogged 'Zaoer-N', but not 'Pepino', hypocotyls. In plants, A and B-type cyclins act in the $\mathrm{G}_{2}$-to-M transition, while D-type cyclins have been implicated in the $\mathrm{G}_{1}$-to-S transition [63, 64]. Four genes encoding mitotic A- and B-type cyclins (Csa7G071600, Csa4G664480, Csa4G658580 and Csa4G664480) were clearly accumulated in 'Zaoer-N', specifically. These findings corroborate those of Arabidopsis, in which the cyclin-dependent kinase activity required for mitosis was regulated by redundant genes encoding CYCLINB and CYCLINA2 [63].

DEGs encoding microtubules (MTs) and MTassociated proteins, such as kinesins, had different expression levels during adventitious rooting. MTs play important roles in cell elongation and division, and they indirectly regulate morphogenesis [65]. Several genes encoding MT and MT-associated proteins, such as Csa5G169090, Csa1G033010, Csa4G101270, Csa3G0 62600, Csa4G293320 and Csa6G382990, were highly expressed in 'Zaoer-N' hypocotyls only, and coincided with the activation of cell division. An increase in the ability to form AR after a subtle perturbation of the MTs has been previously shown for Eucalyptus grandis cuttings [66].

Furthermore, a strong induction of DEGs encoding specific histone variants (Csa7G390230, Csa7G390240, Csa6G193590 and Csa4G290220) were found in 'Zaoer$\mathrm{N}$, whereas two tandemly arrayed DEGs encoding histone deacetylase (Csa6G150540 and Csa6G150550) were induced only in 'Pepino'. In Arabidopsis, the histone variant $\mathrm{H} 3.3$ is associated with active genes and shows a positive correlation with their expression levels, suggesting that histone variant replacement may contribute to 


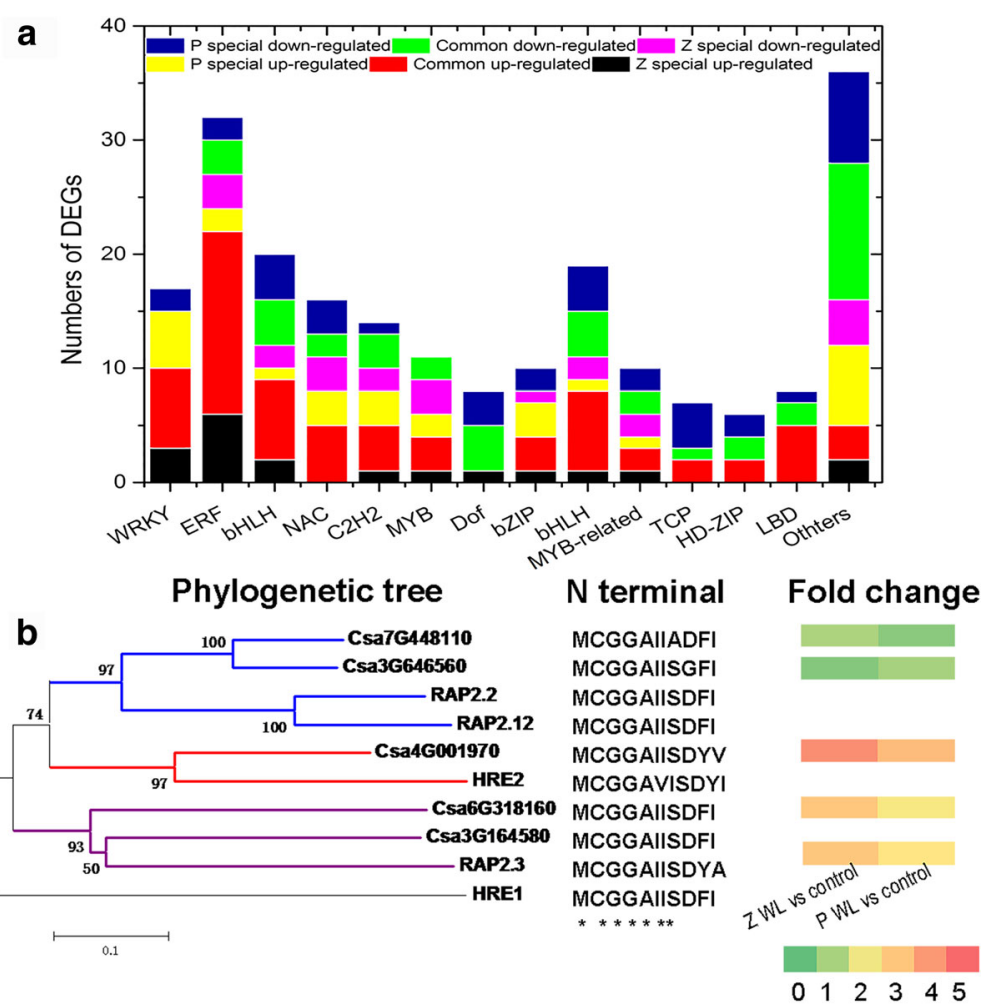

Fig. 5 Response of transcription factors to waterlogging. a Graphical representations of waterlogging-regulated transcription factors based on their assigned protein families. $\mathbf{b}$ The group VII ethylene response factors in cucumber genome. The full-length protein sequences were analyzed with a neighbor-joining method. Numbers above branches represent the bootstrapped value from1000 replicates. RAP2.2 (AT3G14230), RAP2.12 (AT1G53910), HRE2 (AT2G47520), RAP2.3 (AT3G16770) and HRE1 (AT1G72360) were Arabidopsis group VIl ethylene response factors. Asterisks indicate a conserved motif at the N-terminus initiated with Met1-Cys2, as identified by multiple sequence alignment. ' $Z$ WL vs control' represents the fold change of the gene in hypocotyls of 'Zaoer- $N$ ' 2 days after waterlogging treatment than unwaterlogged control; ' $P$ WL vs control' represents the fold change of the gene in hypocotyls of 'Pepino' 2 days after waterlogging treatment than unwaterlogged control

the reprogramming at the developmental transitions in 'Zaoer-N' [67]. By contrast, the Arabidopsis histone deacetylases HDA6 and HDA19 redundantly regulate embryonic genes and negatively affect callus formation from the hypocotyls [68]. Thus, we speculated that an accumulation of histone deacetylases in 'Pepino' may be one of the reasons why the emergence of AR primordia was compromised.

\section{Other identified DEGs}

Our focus on genes with significant roles in AR primordia initiation under waterlogging conditions may provide a restricted view of the large numbers of genes illuminated in this study. Therefore, in this section, other subsets of interesting DEGs are considered to provide a broader view of the molecular mechanisms involved in the waterlogging response.

First, 28 and 26 DEGs encoding cytochrome P450 (CYP) proteins in 'Zaoer-N' and 'Pepino', respectively, were identified. Le Provost et al. [69] also reported the differentially regulation of CYP proteins in the stems of oak seedlings subjected to waterlogging. The gene (Csa5G153010) encoding CYP86A7 showed a peculiar behavior. It was up-regulated in the tolerant genotype 'Zaoer-N' but dramatically down-regulated in the sensitive genotype 'Pepino'. Even though plant CYPs contribute to the biosynthesis and/or catabolism of all phytohormones, pigments, fragrances, flavours, antioxidants, allelochemicals and defense compounds, the eight members of the Arabidopsis CYP86A (from 1 to 8) subfamily have been functionally defined as fatty acid $\omega$-hydroxylases [70]. Increase in free fatty acids have been reported in waterlogged oat and cotton seedlings [71, $72]$. The total level of free fatty acids might increased in waterlogged 'Zaoer-N' hypocotyls because of the significant accumulation of GDSL esterases/lipases, a subclass of lipolytic enzymes that can break down lipids into free fatty acids [2]. The increase in the free fatty acids was presumably due, in part at least, to the synthesis of lipids for new membranes of the AR primordia. However, increased levels of free fatty acids from lipid catabolism might also cause the disruption of membrane structures 
and decreased membrane stability [2]. The expression of the CYP86A gene may thus be involved in prevention of the redundant accumulation of the toxic levels of free fatty acids in waterlogged 'Zaoer-N' hypocotyls. However, the precise roles of other CYPs in the adaptation to the waterlogged conditions remain to be uncovered.

Second, 14 DEGs encoding ankyrin repeat-containing proteins were identified. Among these genes, eight DEGs (Csa1G058080, Csa5G409690, Csa1G058090, Csa3G8 47090, Csa1G058110, Csa6G363020, Csa1G058660 and Csa7G390740) were commonly regulated in both genotypes, while the other six DEGs (Csa3G457650, Csa3G696850, Csa6G008010, Csa1G058160, Csa2G0 10200 and Csa3G822290) were differentially regulated in 'Pepino' only. Du and Chye [73] reported that both of the Arabidopsis ankyrin repeat-containing proteins AtACBP2 and AtACBP4 interact with the group VII ERF protein RAP2.3. Prasad et al. [74] reported that another Arabidopsis ankyrin repeat-containing protein, XBAT32, plays an essential role in ethylene biosynthesis as a negative regulator of ACS protein abundance, and a deletion mutant of XBAT32 led to an increased ethylene production. Thus, the overrepresentation of ankyrin repeat-containing proteins transcripts in 'Pepino' may account for the lack of ACS gene regulation and the relatively lower production of ethylene in this genotype.

A gene (Csa2G406690) encoding sulfite oxidase (SO; EC 1.8.3.1) was observed to be up-regulated in 'Zaoer-N' hypocotyls only. SO oxidizes sulfite to sulfate and, through cytochrome c, transfers the electrons produced to the electron transport chain, allowing for the generation of ATP in oxidative phosphorylation [75]. We hypothesized that the up-regulation of the $S O$ gene might benefit to energy production. Two SOs, CO499223 and CO498687, are also up-regulated in waterlogged cotton roots [76].

\section{Conclusion}

The present comparative RNA-seq study provides new insights into waterlogging-triggered AR primordia initiation in cucumber. The initiation of AR upon waterlogging may be explained in several different ways. First, our results indicate that 'Zaoer- $\mathrm{N}$ ' maintained a more efficient carbohydrate metabolism and regeneration of ATP and $\mathrm{NAD}^{+}$ than the waterlogging-sensitive 'Pepino' to cope with energy crises imposed by waterlogging, thereby favoring greater cell differentiation. Second, ethylene was implicated as a major hormone involved in the cucumber AR primordia initiation. In light of this, and the importance of ethylene responses in the waterlogging phenotypes of other crops, group VII ethylene-responsive TFs are promising candidates for manipulating the waterlogging response. Third, several DEGs related to cell remolding and division were specifically up-regulated in the immersed
'Zaoer-N' hypocotyls cells, while the DEGs that negatively affected callus formation were significantly accumulated only in 'Pepino', coinciding with the different capabilities of the two lines to initiate de novo AR primordia. Upcoming work will aim to characterize the identified individual DEGs to understand their specific functions in waterlogging acclimation and AR formation.

\section{Additional files}

Additional file 1: Table S1. Detailed primer sequences for $\mathrm{qPCR}$
confirmation. (XLS $9 \mathrm{~kb})$

Additional file 2: Figure S1. Comparison of the adventitious root numbers generated in Zaoer-N (left) and Pepino (right) hypocotyls 7 days after waterlogging treatment. (JPEG 977 kb)

Additional file 3: Table S2. Functional annotation of differentially expressed genes identified by RNA-seq in Zaoer-N hypocotyls $48 \mathrm{~h}$ after waterlogging treatment. 'FC' represents fold change of the gene. (XLS $852 \mathrm{~kb}$ )

Additional file 4: Table S3. Functional annotation of differentially expressed genes identified by RNA-seq in Pepino hypocotyls $48 \mathrm{~h}$ after waterlogging treatment. ' $F C^{\prime}$ represents fold change of the gene. (XLS $1012 \mathrm{~kb}$ )

Additional file 5: Table S4. List of differentially expressed genes annotated as transcription factors. (XLS 43 kb)

\begin{abstract}
Abbreviations
1-MCP: 1-methylcyclopropene; ABA: Abscisic acid; ACO: 1-aminocyclopropane1-carboxylicacid oxidase; ACS: 1-aminocyclopropane-1-carboxylicacid synthase; ADH: Alcohol dehydrogenase; ARF: Auxin response factors; ARs: Adventitious roots; CYP: Cytochrome P450; DEGs: Differentially expressed genes; Dof: DNAbinding with one finger; ERFs: Ethylene Response Factor; FDR: False discovery rate; FPKM: Fragments Per Kilobase of exon model per Million mapped reads;

GH3: indole-3-acetic acid-amido synthetases; GO: Gene ontology; IAA: Indole-3-acetic acid; MTs: microtubules; NCED: 9-cis epoxycarotenoid dioxygenase; NsHBs: Non-symbiotic hemoglobins; NTRs: nitrate transporters; PDC: Pyruvate decarboxylase; PIN: Auxin efflux carrier components; QPCR: Quantitative PCR; ROS: Reactive oxygen species; SO: Sulfite oxidase; TFs: Transcription factors; YUC: indole-3-pyruvate monooxygenase YUCCA
\end{abstract}

\section{Acknowledgments}

The authors thank Dr. Axel O. Ramírez-Madera for English language polishing.

\section{Funding}

This research was funded by the National Natural Science Foundation of China (31372087). The authors thank China scholarship council and foundation of excellent doctoral dissertation of Yangzhou University for financial support.

\section{Consent to publication}

Not applicable.

\section{Availability of data and materials}

The raw RNA-seq reads have been deposited in NCBI Sequence Read Archive (SRA) under accession PRJNA328916. The plant material: 'Zaoer-N' and 'Pepino' are homozygous cucumber inbred lines and available upon request. The phylogenetic tree, sequence data and alignments in Fig. 5 b have been deposited to the TreeBASE with the study number 21003. The TreeBase generated URL to access the deposition is http://purl.org/phylo/treebase/phylows/study/TB2:S21003.

\section{Authors' contributions}

$X C$ conceived the experiment. XX performed the research. XX, MC and JJ collected data. XX, QX and XQ analyzed the data and wrote the manuscript. All authors reviewed and approved this submission. 


\section{Ethics approval and consent to participate}

The cucumber landrace Zaoer-N was collected from Fujian, China. The collection of this plant materials comply seriously with the Chinese and international guidelines. Cucumber (Cucumis sativus L.) has not been listed in the appendices I, II and III of the Convention on the Trade in Endangered Species of Wild Fauna and Flora which was validated from Jan 2th, 2017 (https://cites.org/eng/app/appendices.php). The initial collector had deposited the voucher specimen in the Chinese Virture Herbarium in Sep 11th, 1986 with barcode ID: 01178418 (http://www.cvh.ac.cn/spm/PE/ 01178418). Zhang ZY undertook the formal identification.

\section{Competing interests}

The authors declare that they have no competing interests.

\section{Publisher's Note}

Springer Nature remains neutral with regard to jurisdictional claims in published maps and institutional affiliations.

\section{Received: 6 November 2016 Accepted: 21 July 2017}

\section{Published online: 26 July 2017}

\section{References}

1. Zhou J, Qi AG, Zhang YC, Wan SW, Qin P. Adventitious root growth and relative physiological responses to waterlogging in the seedlings of seashore mallow (Kosteletzkya virginica), a biodiesel plant. Aust J Crop Sci. 2012;6(1):73

2. Xu X, Ji J, Ma X, Xu Q, Qi X, Chen X. Comparative proteomic analysis provides insight into the key proteins involved in cucumber (Cucumis sativus L.) adventitious root emergence under waterlogging stress. Front Plant Sci. 2016;(7):1515.

3. Crawford RMM. Oxygen availability as an ecological limit to plant distribution. Adv Ecol Res. 1992;23:93-185.

4. Khatoon A, Rehman S, Oh MW, Woo SH, Komatsu S. Analysis of response mechanism in soybean under low oxygen and flooding stresses using gelbase proteomics technique. Mol Biol Rep. 2012;39(12):10581-94.

5. Bailey-Serres J, Voesenek LACJ. Flooding stress: acclimations and genetic diversity. Annu Rev Plant Biol. 2008;59:313-39.

6. Dawood T, Yang X, Visser EJ, te Beek TA, Kensche PR, Cristescu SM, Lee S, Floková K, Nguyen D, Mariani C, Rieu I. A co-opted hormonal cascade activates dormant adventitious root primordia upon flooding in Solanum Dulcamara. Plant Physiol. 2016;170(4):2351-64.

7. Zhang X, Shabala S, Koutoulis A, Shabala L, Johnson P, Hayes D, Zhou M. Waterlogging tolerance in barley is associated with faster aerenchyma formation in adventitious roots. Plant Soil. 2015;394:355-72.

8. Armstrong W, Justin SHFW, Beckett PM, Lythe S. Root adaptation to soil waterlogging. Aquat Bot. 1991;39:57-73.

9. Blom CW, Voesenek LA, Banga M, Engelaar WM, Rijnders JH, Van de Steeg HM, Visser EJ. Physiological ecology of riverside species: adaptive responses of plants to submergence. Ann Bot. 1994;74(3):253-63.

10. Stanca AM, Romagosa I, Takeda K, Lundborg T, Terzi V, Cattivelli L. Diversity in abiotic stress tolerances. Dev Plant Genet Breed. 2003:7:179-99.

11. Mano Y, Omori F, Loaisiga CH, Bird R. QTL mapping of above-ground adventitious roots during flooding in maize $\times$ teosinte "Zea Nicaraguensis" backcross population. Plant Root. 2009:3:3-9.

12. Kim YH, Hwang SJ, Waqas M, Khan AL, Lee JH, Lee JD, Nguyen HT, Lee IJ. Comparative analysis of endogenous hormones level in two soybean (Glycine max L.) lines differing in waterlogging tolerance. Front. Plant Sci. 2015;6:714.

13. de Klerk GJ, van der Krieken W, de Jong JC. Review the formation of adventitious roots: new concepts, new possibilities. In Vitro Cell Dev Biol. 1999;35(3):189-99

14. Mergemann H, Sauter M. Ethylene induces epidermal cell death at the site of adventitious root emergence in rice. Plant Physiol. 2000;124:609-14

15. Lorbiecke R, Sauter M. Adventitious root growth and cell-cycle induction in deepwater rice. Plant Physiol. 1999;119:21-30.

16. Voesenek LA, Bailey-Serres J. Flood adaptive traits and processes: an overview. New Phytol. 2015;206:57-73.

17. Lin Y, Zhang W, Qi F, Cui W, Xie Y, Shen W. Hydrogen-rich water regulates cucumber adventitious root development in a heme oxygenase-1/carbon monoxide-dependent manner. J Plant Physiol. 2014;171:1-8.
18. Ma J, Aloni R, Villordon A, Labonte D, Kfir Y, Zemach H, Schwartz A, Althan L, Firon N. Adventitious root primordia formation and development in stem nodes of 'Georgia jet' sweetpotato, Ipomoea batatas. Am J Bot. 2015;102(7):1040-9.

19. Xu X, Wang $H$, Qi X, Xu Q, Chen X. Waterlogging-induced increase in fermentation and related gene expression in the root of cucumber (Cucumis sativus L.). Scientia Horticulturae. 2014;179:388-95.

20. Qi XH, Xu XW, Lin XJ, Zhang WJ, Chen XH. Identification of differentially expressed genes in cucumber (Cucumis sativus L.) root under waterlogging stress by digital gene expression profile. Genomics. 2012;99:160-8.

21. Qi XH, Chen RF, Xu Q, Chen XH. Preliminary analysis of submergence tolerance of cucumber at seedling stage. China Vegetables. 2011;4:23-8.

22. Großkinsky DK, Albacete A, Jammer A, Krbez P, van der Graaff E, Pfeifhofer $H$, Roitsch T. A rapid phytohormone and phytoalexin screening method for physiological phenotyping. Mol Plant. 2014;7(6):1053-6.

23. Trapnell C, Roberts A, Goff L, Pertea G, Kim D, Kelley DR, Pimentel H, Salzberg SL, Rinn JL, Pachter L. Differential gene and transcript expression analysis of RNA-seq experiments with TopHat and cufflinks. Nat Protoc. 2012;7(3):562-78.

24. Trapnell C, Williams BA, Pertea G, Mortazavi A, Kwan G, Van Baren MJ, Salzberg SL, Wold BJ, Pachter L. Transcript assembly and quantification by RNA-Seq reveals unannotated transcripts and isoform switching during cell differentiation. Nat Biotec. 2010;28(5):511-5.

25. Voesenek LA, Rijnders JH, Peeters AJ, Van de Steeg HM, De Kroon H. Plant hormones regulate fast shoot elongation under water: from genes to communities. Ecology. 2004;85:16-27.

26. Steffens B, Sauter M. Epidermal cell death in rice is confined to cells with a distinct molecular identity and is mediated by ethylene and $\mathrm{H}_{2} \mathrm{O}_{2}$ through an auto amplified signal pathway. Plant Cell. 2009;21(1):184-96.

27. Huang S, Li R, Zhang Z, Li L, Gu X, Fan W, Lucas WJ, Wang X, Xie B, Ni P, Ren $Y$. The genome of the cucumber, Cucumis sativus L. Nat Genet. 2009;41(12):1275-81.

28. van Veen $H$, Mustroph A, Barding GA, Vergeer-van Eijk M, Welschen-Evertman RA, Pedersen O, Visser EJ, Larive CK, Pierik R, Bailey-Serres J, Voesenek LA. Two Rumex species from contrasting hydrological niches regulate flooding tolerance through distinct mechanisms. Plant Cell. 2013;25(11):4691-707.

29. Cheng XX, Yu M, Zhang N, Zhou ZQ, Xu QT, Mei FZ, Qu LH. Reactive oxygen species regulate programmed cell death progress of endosperm in winter wheat (Triticum aestivum L.) under waterlogging. Protoplasma. 2016;253(2):311-27.

30. $\mathrm{Ma} \mathrm{Q}$, Zhou W, Zhang P. Transition from somatic embryo to friable embryogenic callus in cassava: dynamic changes in cellular structure, physiological status, and gene expression profiles. Front Plant Sci. 2015;6:824.

31. de Carvalho PA, de Oliveira LEM, Sodek L, de Carvalho JN. Nitrogen metabolism in the roots of rubber tree (Hevea brasiliensis) plants supplied with nitrate or ammonium as nitrogen source during hypoxia. Aust J Crop Sci. 2015;9(12):1278

32. Narsai R, Rocha M, Geigenberger P, Whelan J, Van Dongen JT. Comparative analysis between plant species of transcriptional and metabolic responses to hypoxia. New Phytol. 2011;190(2):472-87.

33. Kumutha D, Sairam RK, Ezhilmathi K, Chinnusamy V, Meena RC. Effect of waterlogging on carbohydrate metabolism in pigeon pea (Cajanus cajan L.) upregulation of sucrose synthase and alcohol dehydrogenase. Plant Sci. 2008;175(5):706-16.

34. Ricard B, Van Toai T, Chourey P, Saglio P. Evidence for the critical role of sucrose synthase for anoxic tolerance of maize roots using a double mutant. Plant Physiol. 1998;1 16(4):1323-31.

35. Wang H, Sui X, Guo J, Wang Z, Cheng J, Ma S, Li X. Zhang, Z. Antisense suppression of cucumber (Cucumis sativus L.) sucrose synthase 3 (CSSUS3) reduces hypoxic stress tolerance. Plant Cell Environ. 2014;37(3):795-810.

36. Sousa CA, Sodek L. The metabolic response of plants to oxygen deficiency. Braz J Plant Physiol. 2002;14(2):83-94.

37. Stoimenova M, Igamberdiev AU, Gupta KJ, Hill RD. Nitrite-driven anaerobic ATP synthesis in barley and rice root mitochondria. Planta. 2007;226(2):465-74.

38. Horchani F, Aschi-Smiti S, Brouquisse R. Involvement of nitrate reduction in the tolerance of tomato (Solanum lycopersicum L.) to prolonged root hypoxia. Acta Physiol Plant. 2010;32:1113-23.

39. Huang $X$, von Rad U, Durner J. Nitric oxide induces transcriptional activation of the nitric oxide-tolerant alternative oxidase in Arabidopsis suspension cells. Planta. 2002;215(6):914-23.

40. Perazzolli M, Dominici P, Romero-Puertas MC, Zago E, Zeier J, Sonoda M, Lamb C, Delledonne M. Arabidopsis nonsymbiotic hemoglobin AHb1 modulates nitric oxide bioactivity. Plant Cell. 2004;16(10):2785-94. 
41. Sasidharan R, Voesenek LA. Ethylene-mediated acclimations to flooding stress. Plant Physiol. 2015;169(1):3-12.

42. Xu XW, Ji J, Lu L, Qi XH, Chen XH. Cloning and expression analysis of Cucumis Sativus calcium-dependent protein kinase 5 gene (CSCDPK5) under waterlogging stress. Acta Horticulturae Sinica. 2016;43:704-14.

43. Yang SF, Oetiker $\mathrm{JH}$. The role of ethylene in fruit ripening. Postharvest Physiol Fruits. 1994;398:167-78.

44. Ivanchenko MG, Muday GK, Dubrovsky JG. Ethylene-auxin interactions regulate lateral root initiation and emergence in Arabidopsis Thaliana. Plant J. 2008;55(2):335-47.

45. De Smet I, Signora L, Beeckman T, Inzé D, Foyer CH, Zhang H. An abscisic acid-sensitive checkpoint in lateral root development of Arabidopsis. Plant J. 2003;33:543-55.

46. Schwartz SH, Tan BC, Gage DA, Zeevaart JAD, McCarty DR. Specific oxidative cleavage of carotenoids by VP14 of maize. Science. 1997;276:1872-4.

47. Cox MC, Benschop JJ, Vreeburg RA, Wagemaker CA, Moritz T, Peeters AJ, Voesenek LA. The roles of ethylene, auxin, abscisic acid, and gibberellin in the hyponastic growth of submerged Rumex Palustris petioles. Plant Physiol. 2004;136(2):2948-60.

48. Ding X, Cao Y, Huang L, Zhao J, Xu C, Li X, Wang S. Activation of the indole-3-acetic acid-amido synthetase $\mathrm{GH} 3-8$ suppresses expansin expression and promotes salicylate-and jasmonate-independent basal immunity in rice. Plant Cell. 2008;20(1):228-40.

49. Nakazawa M, Yabe N, Ichikawa T, Yamamoto YY, Yoshizumi T, Hasunuma K, Matsui M. DFL1, an auxin-responsive $\mathrm{GH} 3$ gene homologue, negatively regulates shoot cell elongation and lateral root formation, and positively regulates the light response of hypocotyl length. Plant J. 2001;25(2):213-21.

50. Takase T, Nakazawa M, Ishikawa A, Kawashima M, Ichikawa T, Takahashi N, Shimada H, Manabe K, Matsui M. ydk1-D, an auxin-responsive GH3 mutant that is involved in hypocotyl and root elongation. Plant J. 2004;37(4):471-83.

51. Blilou I, Xu J, Wildwater M, Willemsen V, Paponov I, Friml J, Heidstra R, Aida M, Palme K, Scheres B. The PIN auxin efflux facilitator network controls growth and patterning in Arabidopsis roots. Nature. 2005;433(7021):39-44.

52. Weijers $D$, Jürgens $G$. Auxin and embryo axis formation: the ends in sight? Curr Opin Plant Biol. 2005;8(1):32-7.

53. Yamamoto $Y$, Kamiya N, Morinaka Y, Matsuoka M, Sazuka T. Auxin biosynthesis by the YUCCA genes in rice. Plant Physiol. 2007;143(3):1362-71.

54. Dai X, Mashiguchi K, Chen Q, Kasahara H, Kamiya Y, Ojha S, DuBois J, Ballou D, Zhao Y. The biochemical mechanism of auxin biosynthesis by an Arabidopsis YUCCA flavin-containing monooxygenase. J Biol Chem. 2013;288(3):1448.

55. Cheng Y, Dai X, Zhao Y. Auxin biosynthesis by the YUCCA flavin monooxygenases controls the formation of floral organs and vascular tissues in Arabidopsis. Genes Dev. 2006;20(13):1790-9.

56. de Jong M, Wolters-Arts $M$, Schimmel BC, Stultiens $C L$, de Groot PF, Powers SJ, Tikunov YM, Bovy AG, Mariani C, Vriezen WH, Rieu I. Solanum Lycopersicum AUXIN RESPONSE FACTOR 9 regulates cell division activity during early tomato fruit development. J Exp Bot. 2015;66(11):3405-16.

57. Wang P, Ma L, Li Y, Wang SA, Li L, Yang R, Ma Y, Wang Q. Transcriptome profiling of indole-3-butyric acid-induced adventitious root formation in softwood cuttings of the Catalpa Bungei variety ' $Y U-1$ 'at different developmental stages. Genes Genomics. 2016:38(2):145-62

58. Yamaguchi-Shinozaki K, Shinozaki K. Transcriptional regulatory networks in cellular responses and tolerance to dehydration and cold stresses. Annu Rev Plant Biol. 2006:57:781-803.

59. VEEN H, Akman $M$, Jamar DC, Vreugdenhil $D$, Kooiker $M$, TIENDEREN $P$, Voesenek LA, SCHRANZ M, Sasidharan R. Group VII ethylene response factor diversification and regulation in four species from flood-prone environments. Plant Cell Enriron. 2014;37(10):2421-32.

60. Xu K, Xu X, Fukao T, Canlas P, Maghirang-Rodriguez R, Heuer S, Ismail AM, Bailey-Serres J, Ronald PC, Mackill DJ. Sub1A is an ethylene-response-factorlike gene that confers submergence tolerance to rice. Nature. 2006:442(7103):705-8.

61. Licausi F, Van Dongen JT, Giuntoli B, Novi G, Santaniello A, Geigenberger P, Perata P. HRE1 and HRE2, two hypoxia-inducible ethylene response factors, affect anaerobic responses in Arabidopsis Thaliana. Plant J. 2010;62(2):302-15.

62. Licausi F, Kosmacz M, Weits DA, Giuntoli B, Giorgi FM, Voesenek LA, Perata $P$, van Dongen JT. Oxygen sensing in plants is mediated by an $\mathrm{N}$-end rule pathway for protein destabilization. Nature. 2011;479(7373):419-22.

63. Schnittger A, Schöbinger U, Stierhof YD, Hülskamp M. Ectopic B-type cyclin expression induces mitotic cycles in endoreduplicating Arabidopsis trichomes. Curr Biol. 2002;12(5):415-20.
64. Dewitte W, Scofield S, Alcasabas AA, Maughan SC, Menges M, Braun N, Collins C, Nieuwland J, Prinsen E, Sundaresan V, Murray JA. Arabidopsis CYCD3 D-type cyclins link cell proliferation and endocycles and are rate-limiting for cytokinin responses. Proc Natl Acad Sci U S A. 2007;104(36):14537-42.

65. Landrein B, Hamant O. How mechanical stress controls microtubule behavior and morphogenesis in plants: history, experiments and revisited theories. Plant J. 2013;75(2):324-38.

66. Abu-Abied M, Szwerdszarf D, Mordehaev I, Yaniv Y, Levinkron S, Rubinstein M, Riov J, Ophir R, Sadot E. Gene expression profiling in juvenile and mature cuttings of Eucalyptus grandis reveals the importance of microtubule remodeling during adventitious root formation. BMC Genomics. 2014;15(1):826.

67. Wollmann H, Holec S, Alden K, Clarke ND, Jacques P, Berger F. Dynamic deposition of histone variant $\mathrm{H} 3.3$ accompanies developmental remodeling of the Arabidopsis transcriptome. PLoS Genet. 2012;8(5):e1002658.

68. Tanaka M, Kikuchi A, Kamada H. The Arabidopsis histone deacetylases HDA6 and HDA19 contribute to the repression of embryonic properties after germination. Plant Physiol. 2008;146:149-61.

69. Le Provost G, Lesur I, Lalanne C, Da Silva C, Labadie K, Aury JM, Leple JC, Plomion C. Implication of the suberin pathway in adaptation to waterlogging and hypertrophied lenticels formation in pedunculate oak (Quercus robur L.). Tree Physiol. 2016; tpw056.

70. Renault H, Bassard JE, Hamberger B, Werck-Reichhart D. Cytochrome P450mediated metabolic engineering: current progress and future challenges. Curr Opin Plant Biol. 2014;19:27-34.

71. Liljenberg C. M. Kates. An effect of water stress on lipid composition of oat seedling root cell membranes. In: developments in plant biology, biochemistry and metabolism of plant lipids, Vol. 8, (ed. J.F.G.W. Wintermans and P.J.C. Kuiper), pp. 441-444. Elsevier biomedial. Press BV.

72. Sheikh SA, Shahnawaz M, Baloch SK. 2010. Effect of waterlogging on fatty acid composition of cotton (Gossipium Hirsytum L.) seedling roots. Pak J Agri, Agril Engg Vet Sci. 2010;26(2):1-10.

73. Du ZY, Chye ML. Interactions between Arabidopsis acyl-CoA-binding proteins and their protein partners. Planta. 2013;238(2):239-45.

74. Prasad ME, Schofield A, Lyzenga W, Liu H, Stone SL. Arabidopsis RING E3 ligase XBAT32 regulates lateral root production through its role in ethylene biosynthesis. Plant Physiol. 2010;153(4):1587-96.

75. Hänsch R, Lang $C$, Rennenberg H, Mendel RR. Significance of plant sulfite oxidase. Plant Biol. 2007;9(05):589-95.

76. Christianson JA, Llewellyn DJ, Dennis ES, Wilson IW. Global gene expression responses to waterlogging in roots and leaves of cotton (Gossypium hirsutum L.). Plant Cell Physiol. 2010;51(1):21-37.

\section{Submit your next manuscript to BioMed Central and we will help you at every step:}

- We accept pre-submission inquiries

- Our selector tool helps you to find the most relevant journal

- We provide round the clock customer support

- Convenient online submission

- Thorough peer review

- Inclusion in PubMed and all major indexing services

- Maximum visibility for your research

Submit your manuscript at www.biomedcentral.com/submit 